\title{
A docência nos anos iniciais através da Resolução de Problemas: da formação de professores à implementação de uma aula sobre frações unitárias ${ }^{1}$
}

\author{
Teaching through Problem Solving in Elementary School: from teacher training to the \\ implementation of a class on unitary
}

La docencia en la escuela primaria a través de la Resolución de Problemas: desde la formación del profesorado hasta la implementación de una clase sobre fracciones unitarias

Fábio Vieira Abrão²

Universidade Cruzeiro do Sul (UNICSUL), Cerqueira César, SP, Brasil https://orcid.org/0000-0002-5637-4779, $\Theta$ http://lattes.cnpq.br/9438187179013764

Norma Suely Gomes Allevato ${ }^{3}$
Universidade Cruzeiro do Sul (UNICSUL), São Paulo, SP, Brasil
https://orcid.org/0000-0001-6892-606X, $\Theta$ http://lattes.cnpq.br/9614794595123496

Resumo: Este trabalho apresenta uma implementação de aula no $5^{\circ}$ ano do Ensino Fundamental, inspirada pela Metodologia de Ensino-Aprendizagem-Avaliação de Matemática através da Resolução de Problemas e desenvolvida durante uma formação de professores. Tem-se, como objetivo, analisar como o desenvolvimento de uma formação continuada de professores, em um ambiente on-line, fundamentada na Metodologia de Ensino-Aprendizagem-Avaliação de Matemática através da Resolução de Problemas pode contribuir para o ensino de Matemática. A metodologia adotada foi a da pesquisa qualitativa e os principais procedimentos foram a observação participante e a análise documental das produções das professoras participantes. Os dados foram construídos a partir de uma formação oferecida a nove professoras do $5^{\circ}$ ano do Ensino Fundamental de uma cidade do interior do Estado de São Paulo. Neste artigo, foi analisado o plano de aula elaborado por uma das duplas participantes na atividade de formação, bem como a implementação da referida aula. A metodologia de formação de professores foi o Estudo de Aula, adaptado para o ambiente on-line. Observamos, pela análise do trabalho, um movimento de constituição de diferentes conhecimentos que compõem o conhecimento profissional docente ao planejarem e implementarem a aula fundamentada na Resolução de Problemas. O objetivo das professoras foi atingido, no sentido de promover a compreensão matemática sobre frações unitárias, com ações centradas nos alunos. $O$ relato das professoras sugere que a implementação da Metodologia de Ensino-Aprendizagem-Avaliação de Matemática através da Resolução de Problemas foi satisfatória, uma vez que promoveu a construção de conhecimento pelos alunos no decurso da resolução e da discussão dos problemas propostos, atuando como protagonistas de sua própria aprendizagem.

Palavras-chave: Educação Matemática; Resolução de Problemas; formação docente; estudos de aula.

Abstract: This paper presents a class implementation done in a 5th year class of Elementary School, inspired by the Teaching-Learning-Evaluation Methodology in Mathematics through Problem Solving, which was developed and planned during a teacher training. The main goal is to analyze how the development of teacher training course, offered in a virtual format, based on the Teaching-Learning-Evaluation Mathematics Methodology using Problem Solving might contribute on teaching Mathematics. Qualitative research was the methodology adopted to conduct this work, and the main procedures were based on participant observation and on the analysis of the participant teachers' documental production. The data has been built from a

\footnotetext{
1 Artigo apresentado no I Simpósio de Resolução de Problemas na Educação Matemática (I SiRPEM), da Universidade Estadual de Maringá, Maringá, Paraná, realizado nos dias 29 e 30 de julho de 2021.

2 Currículo sucinto: Licenciado em Matemática pela Universidade Estadual Paulista Júlio de Mesquita Filho (UNESP), mestre em Ensino de Ciências pela Universidade de São Paulo (USP), doutorando em Ensino de Ciências pela Universidade Cruzeiro do Sul (UNICSUL), docente da Escola Técnica Estadual (ETEC). Contribuição de autoria: Escrita - Primeira Redação. Contato: fabio.abrao@etec.sp.gov.br.

3 Currículo sucinto: Licenciada, Bacharel e Mestre em Matemática pela Universidade Estadual de Londrina (UEL), doutora em Educação Matemática pela Universidade Estadual Paulista Júlio de Mesquita Filho (UNESP), docente e coordenadora do Programa de Pós-graduação em Ensino de Ciências e Matemática da Universidade Cruzeiro do Sul (UNICSUL). Contribuição de autoria: Escrita -
} Revisão e Edição. Contato: normallev@gmail.com. 
training offered to nine 5th grade teachers in an elementary school located in the countryside of the State of São Paulo. The current paper is thus focused on the analysis of a lesson plan prepared by a pair of teachers who were participating in the training activity as well as its implementation. Lesson Study was the chosen teacher training methodology that was adapted to suit the online environment. It was observed, through the analysis of the work, a movement towards the constitution of numerous types of knowledge that compose the teacher's general professional knowledge when they plan and implement a class based on Problem Solving. We can argue that the goal of the teachers was reached, in the sense of promoting the mathematical understanding of unitary fractions, using actions centered on the students. This is due to the fact that the teachers' report suggests that the implementation of the Teaching-Learning-Evaluation methodology through Problem Solving in Mathematics was satisfactory when it comes to the fact that it promoted the construction of knowledge by the students, having them act as the protagonists of their own learning during the discussion of the proposed problems.

Keywords: Mathematical Education; Problem Solving; teacher training; lesson study.

Resumen: Este trabajo presenta una implementación de clase en el $5^{\circ}$ año de la Educación Primaria, inspirada en la Metodología Enseñanza-Aprendizaje-Evaluación de las Matemáticas, a través de la Resolución de Problemas, desarrollada durante la formación del profesorado. El objetivo es analizar cómo el desarrollo de la formación continua del profesorado, en un entorno virtual, basado en la metodología Enseñanza-Aprendizaje-Evaluación de las Matemáticas, a través de la Resolución de Problemas, puede contribuir a la enseñanza de las Matemáticas. Se adoptó la metodología de investigación cualitativa y los principales procedimientos fueron la observación participante y el análisis documental de las producciones de los docentes participantes. Se construyeron los datos a partir de una capacitación ofrecida a nueve docentes del quinto año de la escuela primaria en una ciudad del interior del Estado de São Paulo. En este artículo se analizó el plan de lección elaborado por una de las parejas que participaron en la actividad formativa, así como la implementación de dicha clase. La metodología de formación del profesorado fue el Estudio de Aula, adaptado al entorno virtual. Observamos, por vía del análisis del trabajo, un movimiento de constitución de los diferentes saberes que componen el saber docente profesional a la hora de planificar e implementar la clase a partir de la Resolución de Problemas. Se alcanzó el objetivo de los docentes, en el sentido de promover la comprensión matemática sobre fracciones unitarias, con acciones centradas en los estudiantes. El informe docente sugiere que la implementación de la Metodología de EnseñanzaAprendizaje-Evaluación de las Matemáticas a través de la Resolución de Problemas fue satisfactoria, en el sentido de que promovió la construcción de conocimientos por parte de los estudiantes en el curso de la resolución y discusión de los problemas propuestos, haciéndolos actuar como protagonistas de su propio aprendizaje.

Palabras clave: Educación Matemática; Resolución de Problemas; formación de profesores; estudio de clases.

Data de submissão: 29 de setembro de 2021

Data de aprovação: 25 de outubro de 2021

\section{Introdução}

A formação de professores é um campo vasto e, certamente, relevante, tanto no que se refere à formação inicial, desenvolvida nas licenciaturas, quanto à formação continuada, em serviço ou não. Não obstante tantas experiências já realizadas pelas pesquisas e práticas consolidadas, a busca por melhores resultados neste campo e por ajudar, de modo adequado, a promover o desenvolvimento profissional docente sempre se justifica, tendo em vista a necessidade constante de melhoria da qualidade do ensino. Uma dessas práticas, que tem sido explorada especialmente no âmbito da pesquisa, refere-se aos Estudos de Aula, entre as quais podemos citar as desenvolvidas por Fiorentini (2011), Borelli (2019) e Utimura (2019), entre outros 
que serão mencionados no presente estudo. Esta metodologia de formação de professores, conforme tem sido denotada pelos autores, será, aqui, objeto de reflexão, uma vez que foi utilizada na experiência a partir da qual se constituíram os dados analisados.

No que se refere a abordagens de ensino, colocamos no foco a Resolução de Problemas que, considerada o coração da atividade matemática, ganha destaque nos atuais documentos de orientação curricular, a saber: a Base Nacional Comum Curricular - BNCC (BRASIL, 2018) e os currículos locais - estaduais e municipais - a partir dela reelaborados. Conforme se apresenta na BNCC, a resolução de problemas, entre outros processos matemáticos, constitui-se em forma privilegiada da atividade matemática, motivo pelo qual deve ser, ao mesmo tempo, objeto e estratégia para a aprendizagem ao longo de todo o Ensino Fundamental. Voltando a atenção ao termo "estratégia", fomos levados a considerar os trabalhos desenvolvidos nesta linha por Allevato e Onuchic (2014), que consideram, recomendam e fornecem orientações para o trabalho com resolução de problemas, tomando-os como ponto de partida e orientação para a aprendizagem de novos conceitos e novos conteúdos matemáticos, em todos os níveis de ensino. As autoras chamam esta forma de trabalho de Metodologia de Ensino-Aprendizagem-Avaliação de Matemática através da Resolução de Problemas - MEAAMARP.

Desse modo, o presente trabalho foi desenvolvido a partir de um recorte dos dados coletados para a pesquisa de doutorado do primeiro autor, cujo objetivo é investigar como o desenvolvimento de uma formação continuada de professores em um ambiente on-line, fundamentado na Metodologia de Ensino-Aprendizagem-Avaliação de Matemática através da Resolução de Problemas, pode contribuir para o ensino de Matemática. A coleta de dados foi realizada a partir de uma formação on-line oferecida a nove professoras (organizadas em três duplas e um trio) que ensinam, ou ensinaram, Matemática no $5^{\circ}$ ano do Ensino Fundamental. Analisamos, neste artigo, o planejamento e a execução de uma aula sobre frações unitárias, elaborado por uma das duplas desse grupo.

Como metodologia de formação de professores, utilizamos os Estudos de Aula (Lesson Study), de acordo com as concepções de Utimura (2019), adaptada para o ambiente on-line. Os encontros síncronos permitiram discussões teóricas sobre os Estudos de Aula, além de vivências da MEAAMARP, de acordo com as concepções de Allevato e Onuchic (2014).

No presente artigo, apresentaremos alguns fundamentos teóricos acerca de formação de professores e sobre a metodologia de ensino, a Resolução de Problemas, que embasam nossa pesquisa. Aspectos da metodologia de pesquisa são delineados. Prosseguimos com uma análise sobre a participação de uma dupla de professoras ao implementar uma aula fundamentada na Resolução de Problemas, conforme abordado na formação oferecida, bem como suas percepções no decorrer dos encontros. Registramos nossas observações e discutimos os dados coletados 
relacionando-os com os fundamentos teóricos adotados para a análise. Concluímos com as considerações finais e as referências.

\section{Referencial Teórico}

\subsection{Estudo de Aula}

A metodologia de formação de professores adotada no presente estudo foi o Estudo de Aula, adaptada para o ambiente virtual, de modo que as participantes pudessem refletir criticamente sobre a sua prática profissional, com especial abordagem à Resolução de Problemas. Esta perspectiva metodológica tem origem no Japão, onde recebeu o nome de Jyugyo Kenkyuu. É uma atividade necessariamente realizada em grupo, na qual professores planejam uma aula colaborativamente e realizam observações de sua própria prática e dos outros integrantes do grupo, com o objetivo de melhorar a aprendizagem dos alunos, além de contribuir com a melhoria de sua prática de ensino (UTIMURA, 2019).

Dito de outro modo, essa metodologia tem por objetivo observar a aprendizagem dos alunos após uma aula planejada por um grupo de professores e ministrada por um deles. Após a observação, o grupo reflete sobre o desenvolvimento da aula em função dos objetivos propostos e pode reformular o plano de aula para uma nova aplicação, por outro membro do grupo, a uma nova turma de alunos, caso haja possibilidade. Essa metodologia corrobora as principais ideias de Ponte et al. (2012) no sentido de construir um espaço formativo baseado na reflexão, colaboração e investigação, culminando em melhorias na prática docente.

Utimura (2019) sugere que os Estudos de Aula se efetivem em etapas que compõem um ciclo conforme Figura 1.

Figura 1 - Etapas do Estudo de Aula

\begin{tabular}{|l|l||}
\hline $\begin{array}{l}\text { Escolha de objetivos para as } \\
\text { aprendizagens e desenvolvimento dos } \\
\text { alunos. }\end{array}$ \\
\hline $\begin{array}{l}\text { Planejamento de uma aula baseada } \\
\text { nesses objetivos. }\end{array}$ \\
\begin{tabular}{|l|l||} 
Observação da aula implementada e \\
coleta de dados sobre as \\
aprendizagens e o desenvolvimento dos \\
alunos.
\end{tabular} \\
\hline $\begin{array}{l}\text { Uso dos dados para refletir de forma } \\
\text { ampla sobre a aula e sobre as etapas } \\
\text { anteriores. }\end{array}$
\end{tabular}

Fonte: Utimura (2019, p. 27). 
O ciclo pode ser repetido diversas vezes, enquanto houver sugestões para a melhoria da aula. Desse modo,

O Estudo de Aula pode tornar as abordagens de ensino mais práticas e compreensíveis para o professor, e como consequência disto, os estudantes podem ter melhor compreensão sobre o assunto estudado e também sobre o desenvolvimento do seu próprio pensamento. Dessa maneira, o Estudo de Aula estabelece uma relação direta entre a teoria e a prática. (BORELLI, 2019, p. 40).

A contribuição para o desenvolvimento profissional do professor é apontada como aspecto relevante em todos os países onde o Estudo de Aula foi aplicado. Desta forma, consideramos que essa metodologia de formação de professores corrobora os estudos de Shulman $(1986,1987)$, no sentido de contribuir para a construção do conhecimento do professor. Em Shulman (1987), são descritas sete categorias que compõem o conhecimento do professor, destacando a importância de se conhecer o contexto educacional onde se vai lecionar e quais dinâmicas de sala de aula influenciam no processo de ensino-aprendizagem.

As categorias são: o conhecimento do conteúdo; o conhecimento pedagógico geral; o conhecimento do currículo; o conhecimento pedagógico do conteúdo; o conhecimento dos alunos e suas características; o conhecimento dos contextos educacionais; o conhecimento dos objetivos, das finalidades e dos valores educacionais e de seus fundamentos filosóficos e históricos. Dentre elas destacamos, no Quadro 1, as que se relacionam às observações realizadas neste trabalho, caracterizando-as a partir das ideias de Shulman (1987).

Quadro 1 - Categorias consideradas

\begin{tabular}{|l|l|}
\hline Conhecimento pedagógico geral & $\begin{array}{l}\text { Conhecimento necessário para que o professor conduza o seu } \\
\text { trabalho dentro e fora da sala de aula. }\end{array}$ \\
\hline $\begin{array}{l}\text { Conhecimento pedagógico do } \\
\text { conteúdo }\end{array}$ & $\begin{array}{l}\text { Conhecimento que se relaciona simultaneamente ao conhecimento } \\
\text { do conteúdo específico e ao conhecimento pedagógico, determinando } \\
\text { o que deve ser ensinado e de que maneira. }\end{array}$ \\
\hline $\begin{array}{l}\text { Conhecimento dos alunos e suas } \\
\text { características }\end{array}$ & $\begin{array}{l}\text { Conhecimento da forma como os alunos aprendem, de acordo com a } \\
\text { realidade social em que estão inseridos, com os seus conhecimentos } \\
\text { prévios e com as diferentes maneiras como eles pensam. }\end{array}$ \\
\hline $\begin{array}{l}\text { Conhecimento dos objetivos, das } \\
\text { finalidades e dos valores } \\
\text { educacionais e de seus } \\
\text { fundamentos filosóficos e históricos }\end{array}$ & $\begin{array}{l}\text { Conhecimento que se refere à compreensão da função da escola na } \\
\text { história e na comunidade em que se insere, bem como de suas metas } \\
\text { e visão de futuro, possibilitando ao professor promover ações, junto } \\
\text { aos alunos, de modo a colaborar com os objetivos da instituição. }\end{array}$ \\
\hline
\end{tabular}
Fonte: Shulman (1987).

Consideramos que os estudos de Shulman $(1986,1987)$ são significativas referências na atualidade, tendo sido adaptados para diferentes áreas do conhecimento. $O$ objetivo é compreender o ensino real da Matemática, identificando o conhecimento matemático necessário para o ensino com base em análises das práticas em sala de aula.

No ambiente em que a formação dos professores foi realizada por nós, houve a discussão em grupo sobre a (re)elaboração de planos de aula. Esses planos envolveram conteúdos 
matemáticos escolhidos pelos próprios docentes e fundamentaram-se na Metodologia de EnsinoAprendizagem-Avaliação de Matemática através da Resolução de Problemas. Por isso, dedicamos a próxima seção à Resolução de Problemas.

\subsection{Resolução de Problemas}

A abordagem de práticas através da (ou via) Resolução de Problemas "tem forte impacto no desenvolvimento profissional docente, é a investigação sobre a própria prática de ensinar/aprender em um ambiente exploratório-investigativo" (FIORENTINI, 2011, p. 7). Assim, concordando que os atos de pensar e agir em ambientes de formação de professores podem contribuir para melhorias efetivas nas práticas de formação e no trabalho satisfatório em sala de aula, consideramos que a resolução de problemas não deve ser negligenciada nesse trabalho com a Matemática. Desse modo, vamos ressaltar aspectos fundamentais sobre a MEAAMARP, pois, durante a formação aqui apresentada e analisada, os professores tiveram ampla vivência nessa metodologia de ensino de Matemática.

$\mathrm{Na}$ pesquisa que desenvolvemos, em particular, adotamos a vertente da MEAAMARP descrita por Allevato e Onuchic (2014) por considerar que, em sala de aula, as tarefas e as atividades matemáticas baseadas na resolução de problemas "são o veículo pelo qual se pode desenvolver o currículo desejado. A aprendizagem é um resultado do processo de resolução de problemas" (VAN DE WALLE, 2009, p. 58).

Nesta forma de trabalho, o ensino, a aprendizagem e a avaliação de Matemática podem acontecer em vários momentos de uma aula e sem, necessariamente, serem atribuições somente do professor ou somente do aluno. Além disso, todos os envolvidos nesses processos podem ser coautores e corresponsáveis pela aula, pelas aprendizagens e pela avaliação dessas aprendizagens. Quando ocorrem de forma integrada na sala de aula, os termos ensino e aprendizagem dão espaço à expressão composta ensino-aprendizagem, frequentemente utilizada em textos acadêmicos. Avançando neste raciocínio e havendo a necessidade de considerar a avaliação como um processo contínuo, formativo e integrado ao ensino e à aprendizagem, justifica-se o emprego da expressão ensino-aprendizagem-avaliação, tendo a avaliação integrada à resolução de problemas, com o objetivo de acompanhar o crescimento dos alunos aumentando a aprendizagem e servindo como critério de reorganização das práticas de sala de aula (ONUCHIC et al., 2014).

Na MEAAMARP, o problema é o ponto de partida e orientação para a aprendizagem de um novo conteúdo matemático. Esse é o problema gerador, que desencadeia no aluno o interesse em resolvê-lo, porém sem ter (ou indicar) um método, algoritmo ou fórmulas específicas para tal. Desse modo, Allevato e Onuchic (2014, p. 44) ressaltam que um "problema se configura na 
relação com o resolvedor, de tal modo que, se ele já conhece ou tem memorizados tais métodos de resolução ou não está interessado na atividade, não será para ele um problema".

De acordo com o exposto, desenvolvemos com os professores as atividades considerando as dez etapas da MEAAMARP sugeridas por Allevato e Onuchic (2014), aos moldes do que os próprios professores fariam com seus alunos em aula. A seguir, abordaremos cada uma dessas etapas propostas pelas autoras.

(1) Proposição do problema - O problema gerador é o ponto de partida e orientador da aprendizagem do novo conteúdo matemático. É importante ressaltar que, para que o problema seja de fato um problema gerador, o conteúdo matemático necessário ou mais apropriado para a resolução que se pretende abordar naquela aula não tenha ainda sido trabalhado com os alunos, de modo a incentivar a multiplicidade de soluções e não apenas uma mera aplicação de passos pré-determinados.

(2) Leitura individual - A leitura do problema é realizada primeiro individualmente para que, a partir dela, cada aluno possa refletir sobre o problema e iniciar a resolução, de acordo com a sua interpretação particular do enunciado, recorrendo aos seus conhecimentos prévios.

(3) Leitura em conjunto - Reunidos em pequenos grupos (de 2 ou 3 alunos), os alunos podem sanar algumas dúvidas com os colegas. Se houver dificuldade na leitura do texto, o próprio professor pode auxiliá-los. Caso existam, no texto do problema, palavras desconhecidas para os alunos, surge uma segunda dificuldade. Busca-se uma forma de poder esclarecer as dúvidas e, se necessário, pode-se, com os alunos, consultar um dicionário.

(4) Resolução do problema - Sem dúvidas quanto ao enunciado, os alunos, em seus grupos, em um trabalho cooperativo e colaborativo, buscam resolvê-lo. Os alunos são os protagonistas do processo de resolução do problema gerador, cujo principal objetivo é conduzi-los para a construção do conteúdo planejado pelo professor para aquela aula.

(5) Incentivar e observar - O professor não tem mais o papel de transmissor do conhecimento. Enquanto os alunos, em grupo, buscam resolver o problema, o professor observa, analisa o comportamento dos alunos e estimula o trabalho colaborativo. O professor pode responder às dúvidas apresentadas pelos alunos, porém é necessário que o professor assuma uma postura de questionador, levando os alunos a pensar e construir a resolução do problema utilizando seus conhecimentos prévios e suas formas próprias de representação e de resolução.

(6) Registro das resoluções na lousa - Cada grupo escolhe um representante para expor a resolução do grupo na lousa. Resoluções certas, erradas ou feitas por diferentes processos devem ser apresentadas para que todos os alunos as analisem e discutam.

(7) Plenária - Todos os alunos participam das discussões acerca das resoluções registradas na lousa. Eles defendem seus pontos de vista e explicam a resolução do grupo. $O$ 
professor medeia e incentiva as discussões, construindo um momento de reflexão e debate, que conduzirá à aprendizagem.

(8) Busca do consenso - Esta etapa finaliza a plenária, em que o professor tenta obter um consenso com toda a turma sobre a resolução (ou resoluções) correta(s) para o problema gerador.

(9) Formalização do conteúdo - O professor, então, formaliza os conceitos, princípios e procedimentos matemáticos planejados para aquela aula e que, possivelmente, já foram abordados nas resoluções desenvolvidas pelos alunos ou poderiam ser empregados na resolução do problema gerador, destacando as diferentes técnicas operatórias e as demonstrações das propriedades associadas àquele assunto, se necessário.

(10) Proposição e resolução de novos problemas - De acordo com os resultados obtidos, os alunos são convidados a formular e resolver novos problemas derivados das discussões realizadas. Nessa etapa, o professor pode analisar a compreensão do conteúdo matemático introduzido e trabalhado através da resolução do problema gerador, além de consolidar as aprendizagens pretendidas para a aula e aprofundar os conhecimentos matemáticos relacionados ao problema gerador.

\section{Metodologia da Pesquisa}

Neste estudo, adotamos a metodologia qualitativa de pesquisa por entendermos que o aprofundamento da compreensão do grupo social estudado é mais relevante do que seria sua representatividade numérica, considerando o objetivo do nosso estudo (GOLDENBERG, 2011).

Os principais procedimentos de pesquisa que utilizamos tiveram o intuito de organizar as ações para que a formação contribua com o desenvolvimento profissional dos participantes e que sejam significativos para a coleta de dados da pesquisa. Sendo assim, pesquisa e ensino se combinam e se complementam, pois os dados coletados têm como fonte um grupo de formação continuada de professoras que ensinam Matemática. Os principais procedimentos foram, assim, a observação participante e a análise documental das fontes produzidas pelas professoras participantes (planos de aula, reflexões escritas sobre textos lidos e experiências vivenciadas, resoluções de problemas desenvolvidas durante a formação).

A coleta de dados foi realizada a partir de uma prática de formação on-line oferecida a docentes atuantes, ou que já atuaram, no $5^{\circ}$ ano do Ensino Fundamental, na rede municipal de ensino de uma cidade no interior do Estado de São Paulo. Esta rede de ensino realiza formações continuadas em diversas áreas do conhecimento, oferecidas por profissionais e gestores atuantes na própria rede, como coordenadores pedagógicos e diretores, ou por meio de parcerias com 
instituições de ensino superior, e nos abriu espaço para esta formação, relacionada ao ensino de Matemática.

A formação contou com nove participantes e foi realizada de maneira totalmente remota, com carga horária de 60 horas, das quais 40 horas em encontros síncronos, nos quais as professoras participantes puderam vivenciar a MEAAMARP, com temas matemáticos sugeridos previamente por elas mesmas. Outras 20 horas de atividades foram assíncronas, nas quais as participantes puderam realizar, antecipadamente a cada encontro, estudos sobre os temas que seriam desenvolvidos nos encontros síncronos, preparando-se para eles. As ações da formação tiveram o Estudo de Aula como metodologia de formação de professores.

Cada encontro síncrono tinha como tema um dos conteúdos matemáticos escolhidos pelas professoras e, como foco, a MEAAMARP. Conforme já indicado, na referida metodologia, o trabalho inicia-se com a proposição de um problema, chamado problema gerador, neste caso escolhido pelo pesquisador, e as demais etapas se desenvolviam ora em pequenos grupos, ora em plenária, conforme as sugestões de Allevato e Onuchic (2014).

Posteriormente à vivência da MEAAMARP com vários temas matemáticos ao longo de vários encontros, as professoras participantes elaboraram, em duplas ou trios, planos de aula identificando os objetivos que pretendiam atingir com suas respectivas turmas, em um ensino baseado na MEAAMARP. No momento do planejamento da aula, as duplas e os trios formados pelas professoras, orientadas pelo pesquisador, anteciparam possíveis respostas dos alunos, diferentes estratégias empregadas para a resolução do problema gerador proposto, e buscaram detalhar ao máximo a aula. Recomendamos que revisitassem as orientações curriculares, pois acreditamos que essa etapa poderia contribuir com o desenvolvimento dos conhecimentos específicos sobre o conteúdo escolhido pela dupla para o plano de aula e sobre os objetivos do ensino. Após a elaboração dos planos, as professoras apresentaram a versão final para o grupo das nove professoras participantes da formação.

Detalharemos o desenvolvimento e a aplicação da aula sobre frações unitárias, de uma dupla de professoras identificadas, a seguir, como $\mathrm{M}$ e $\mathrm{P}$.

\section{Resultados e Discussão}

$\mathrm{M}$ e $\mathrm{P}$ são professoras que já atuaram no $5^{\circ}$ ano do Ensino Fundamental e no momento da formação estavam lecionando para turmas de $4^{\circ}$ ano. A turma da professora $\mathrm{P}$, que contava com 26 alunos com idades de 9 e 10 anos, foi a escolhida para a realização da aula planejada. A aula 
foi preparada para ser ministrada de forma remota ${ }^{1}$, combinando momentos síncronos e assíncronos.

Diariamente a professora vinha ministrando suas aulas de forma remota, porém, nem todos os alunos conseguiam participar das aulas síncronas por não terem um adulto para acompanhá-los ou por dependerem de um equipamento que não estava disponível naquele horário. Então, a aula era gravada e permanecia disponível para que esses alunos pudessem assisti-la em outro momento.

$\mathrm{Na}$ aula síncrona aqui relatada, estavam presentes 14 alunos, que puderam interagir com as professoras $\mathrm{M}$ e $\mathrm{P}$. A professora $\mathrm{P}$ foi a responsável pela condução da aula e a professora $\mathrm{M}$ atuou como observadora.

Apesar da interação síncrona ser fundamental para o desenvolvimento da aula planejada, as professoras propuseram que os alunos que não pudessem estar presentes sincronamente assistissem ao momento de formalização, etapa 9 da MEAAMARP, disponibilizado também em gravação de vídeo. Assim, a falta de acesso poderia ser parcialmente compensada com relação ao pretendido naquela aula.

A fim de facilitar ao leitor, reproduzimos na Figura 2 um esquema que representa as etapas da metodologia, conforme já expusemos anteriormente.

Figura 2 - Etapas da MEAAMARP

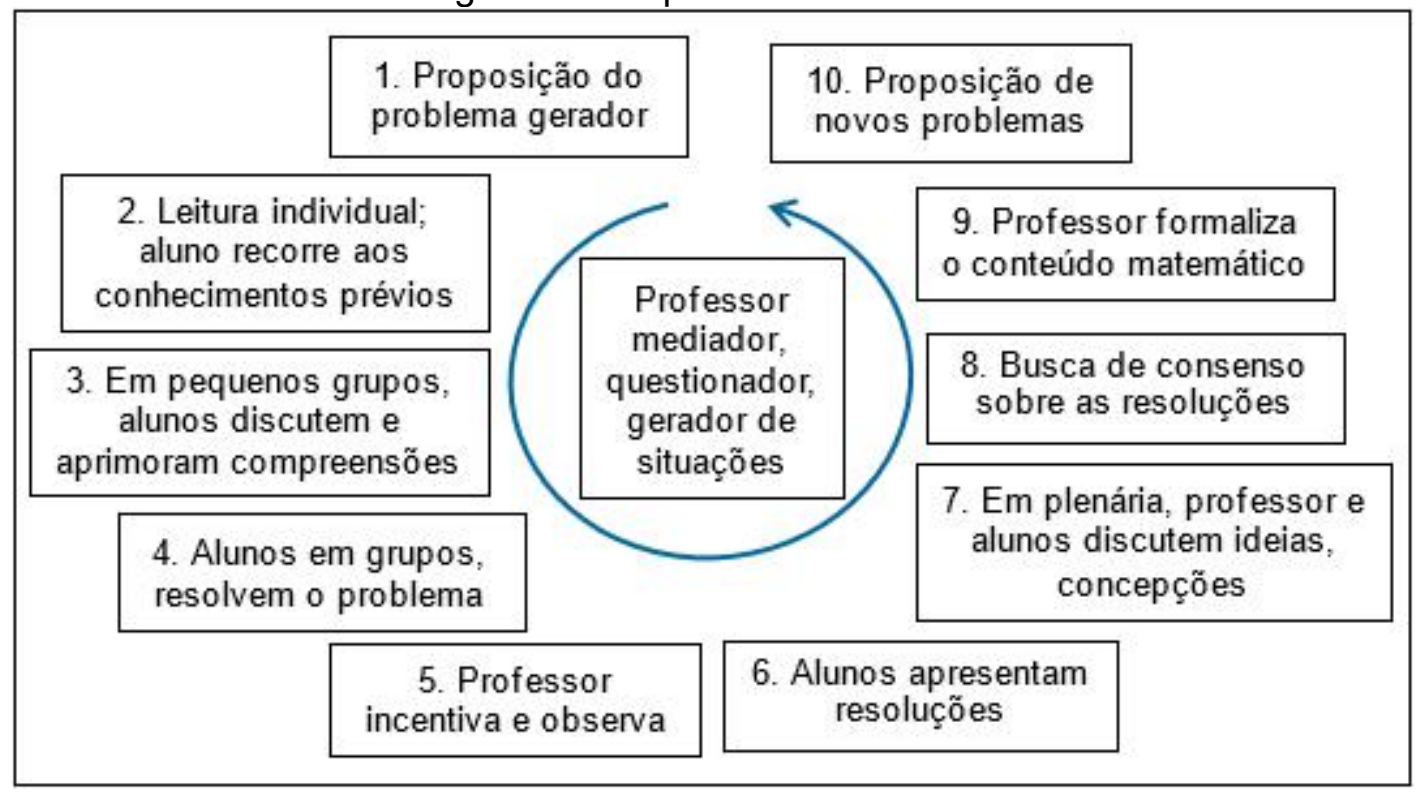

Fonte: Allevato e Onuchic (2021, em vias de publicação).

${ }^{1} \mathrm{~A}$ formação foi realizada no momento de distanciamento social em virtude da pandemia de COVID-19, no primeiro semestre de 2021. 
Consideramos que, com essa iniciativa, as professoras demonstraram estar de posse de aspectos ligados ao conhecimento dos alunos e suas características, de acordo com as concepções de Shulman (1987), uma vez que conheciam os recursos e as condições desses alunos ou a falta deles, adotando providências para auxiliar os alunos com relação a isso.

Durante a elaboração do plano de aula, as professoras desenvolveram seu conhecimento pedagógico geral ao organizar a metodologia de ensino. O plano de aula foi estruturado de modo que as ações de ensino fossem orientadas pela MEAAMARP, podendo ter algumas de suas etapas adaptadas para o ensino remoto. Ao realizar tais adaptações, as professoras demonstraram conhecimento pedagógico do conteúdo, percebendo quais as ferramentas adequadas para o desenvolvimento do conteúdo específico pretendido, em um ambiente totalmente on-line.

$\mathrm{Na}$ Figura 3, reproduzimos o problema gerador, estruturado em três partes (itens $a, b$ e c), formulado pelas professoras M e P para trabalhar o conteúdo frações unitárias.

Figura 3 - Problema gerador

Hoje, o $4^{\circ}$ ano $\mathrm{B}$ irá dividir "chocolates". Os alunos irão utilizar folhas de sulfite ou de caderno para representar as barras de chocolates e resolver os problemas propostos

a) Você deverá pegar a primeira barra e dividi-la igualmente entre você e uma outra pessoa, como isso pode ser realizado?

b) Agora, com a segunda barra de chocolate, faça a divisão para três pessoas.

c) Por fim você irá dividir igualmente a terceira barra de chocolate para quatro pessoas.

Fonte: Material da pesquisa.

Para esse problema, o foco pretendido pelas professoras era o trabalho de identificação das frações unitárias mais usuais, como partes do inteiro, e as estratégias de resolução envolvem a divisão de uma folha de papel em partes iguais, de modo que representem as frações solicitadas.

Conforme os passos sugeridos para o trabalho através da resolução de problemas, de Allevato e Onuchic (2014), a aula iniciou-se com a proposição do problema aos alunos da professora P. O problema envolve conceitos que eles já conheciam (divisão em partes iguais), de modo que o esperado era que esses conhecimentos prévios permitissem que um novo conhecimento fosse construído: a identificação de frações unitárias.

Iniciando as atividades, o problema foi proposto para que os alunos o resolvessem em grupos. A professora ministrante não disse de qual conteúdo o problema tratava. Os alunos 
poderiam representar as barras de chocolate como quisessem, inclusive pintando com suas cores preferidas e as estratégias de resolução escolhidas por cada grupo não eram classificadas, em princípio, como certas ou erradas pela professora, que apenas observava e incentivava as ações. Após alguns minutos do início das atividades, a professora $P$ observou que três alunos apresentavam grande dificuldade em compreender o problema. $\mathrm{P}$ considera que tal dificuldade ocorreu devido ao processo de alfabetização ainda estar incompleto com esses alunos, pois eles tinham dificuldade em ler o enunciado.

Então, a professora $\mathrm{P}$ realizou uma leitura cuidadosa do problema com esses alunos, porém sem indicar qualquer estratégia para a resolução do problema. Considerando a importância de estimular a troca de ideias entre os alunos, central nesta etapa do trabalho em pequenos grupos, $\mathrm{P}$ tentava auxiliá-los a superar suas dificuldades. Fazia questionamentos e os ajudava a organizar seus próprios pensamentos a partir de suas compreensões iniciais e conhecimentos prévios. Trata-se, aqui, de o professor mobilizar o "conhecimento dos alunos e suas características", uma das categorias consideradas por Shulman (1987), tendo sido decisivo o conhecimento da professora de que esses alunos tinham carências de alfabetização para que sua atitude/ação proporcionasse que tivessem bom aproveitamento na atividade. Ademais, nos Princípios e Padrões para a Matemática Escolar (NCTM, 2000, tradução nossa), encontramos indicações sobre o trabalho do professor ao ajudar seus alunos a resolver problemas. $O$ documento ressalta que é provável que os alunos desenvolvam confiança e segurança na sua capacidade de resolver problemas em um ambiente onde suas ideias são respeitadas e valorizadas. Assim, com a compreensão do problema, os alunos retomaram o trabalho de resolução. $\mathrm{P}$ ressalta o entusiasmo dos alunos ao resolverem o problema com sucesso após a intervenção.

Outros grupos solicitaram a ajuda de $\mathrm{P}$, principalmente para que a professora confirmasse se a estratégia adotada pelo grupo estava correta. $\mathrm{P}$ respondia às questões com outras perguntas, incentivando todos os membros do grupo a participar. Um aluno questionou: "Professora, posso repartir a folha desse jeito?" (Indicando uma dobra vertical na folha). P responde dirigindo a palavra a outro aluno do grupo e questiona: "O que você acha? Seu amigo pode dobrar a folha assim?". O aluno indagado, então, entra na discussão: "Eu não fiz assim; eu dobrei desse jeito (indicando uma dobra horizontal). Mas acho que também está certo". P interfere novamente: "Por que você acha que as duas dobras estão corretas?". O aluno responde: "As duas crianças vão ganhar pedaços de chocolate do mesmo tamanho."

Van de Walle (2009) destaca que permitir que os alunos comparem resoluções e que percebam e corrijam (se necessário) seus próprios erros colabora com o surgimento das melhores discussões, que tendem a aparecer quando há divergência de pensamentos. Nesse sentido, 
podemos observar que a intervenção de $\mathrm{P}$ conduziu o grupo a elaborar e pensar sobre diferentes resoluções e soluções para o problema de modo que os próprios integrantes pudessem verificar a validade de ambas, sendo capazes de defender seus argumentos com propriedade. A etapa da discussão em grupo possibilitou que os alunos corrigissem seus próprios erros e nenhum grupo finalizou a resolução do problema incorretamente. De qualquer modo, se houvesse resoluções incorretas, na etapa de plenária elas seriam discutidas, com respeito e espírito de colaboração, em uma perspectiva de considerar o erro como parte integrante do processo de resolução de problemas e da aprendizagem. Vale destacar, ainda, que a ajuda precoce da professora poderia privá-los da oportunidade de fazer descobertas matemáticas e de justificar seus procedimentos e pensamentos (NCTM, 2000).

Posteriormente, todos os alunos foram convidados a expor suas resoluções aos demais colegas da turma. P ressalta a sua surpresa ao perceber que, na construção da fração um terço, alguns alunos recorreram espontaneamente ao uso da régua, pois não encontraram uma maneira eficaz de divisão da folha em três partes iguais. Os alunos demonstraram iniciativa e autonomia ao recorrer ao uso de ferramentas não solicitadas ou indicadas pela professora. Ocorre que, quando os alunos partilham as suas soluções com os colegas, os professores podem ajudá-los a analisar vários aspectos das suas estratégias. Além disso, simples descrições de procedimentos cedem lugar a argumentos matemáticos (NCTM, 2000).

A professora observadora $\mathrm{M}$ ressaltou que a resolução do item c, proposto no problema, foi feita muito rapidamente por alguns grupos. Ela ficou surpresa com a inferência realizada pelos alunos, que chegaram à fração um quarto repartindo ao meio a fração correspondente à metade (obtida no item a). Este fato mostra como os alunos se tornaram "mais experientes" com as resoluções de problemas, utilizando resultados anteriores.

Polya (1994) destaca a importância em tornar os alunos autônomos em resolver problemas, porém com um importante papel atribuído ao professor de direcionar as indagações para estimular generalizações.

A resolução de problemas é uma habilitação prática como, digamos, o é a natação. Adquirimos qualquer habilitação por imitação e prática. [...] Ao tentarmos resolver problemas, temos de observar e imitar o que fazem outras pessoas quando resolvem os seus e, por fim, aprendemos a resolver problemas, resolvendo-os. (POLYA, 1994, p. 3).

Outro ponto positivo destacado pela professora $M$ foi a apresentação dos alunos não alfabetizados. Eles também conseguiram traçar estratégias para a resolução do problema e conseguiram justificar suas escolhas oralmente. A leitura do problema realizada por $P$ realmente possibilitou que a dificuldade com a compreensão fosse superada.

Para a formalização do conteúdo foram adotadas duas estratégias. Conforme apontado anteriormente, a professora $\mathrm{P}$ teve alunos que não puderam assistir às aulas em tempo real e, 
para que não "perdessem a explicação da professora", um vídeo foi gravado anteriormente com a formalização do conteúdo trabalhado. A segunda estratégia foi a formalização realizada durante a videochamada, utilizando os mesmos slides gravados para a formalização assíncrona, porém permitindo a interação com os alunos em tempo real (Figura 4).

\section{Figura 4 - Trecho da aula assíncrona da professora $\mathrm{P}$}

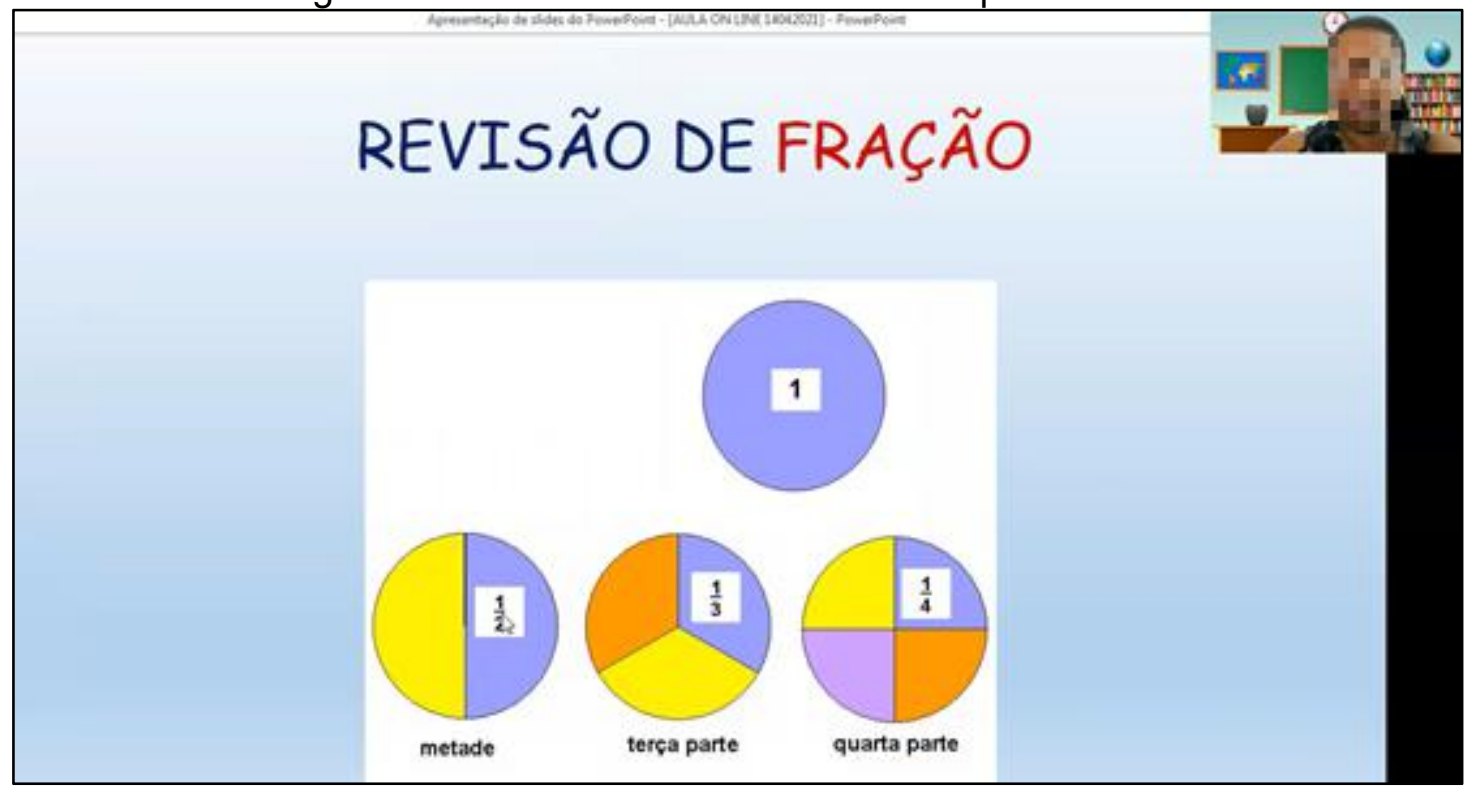

Fonte: Material da pesquisa.

A professora M destacou que, durante a formalização, os alunos se antecipavam, identificando a representação formal das frações unitárias trabalhadas, relacionando-as aos desenhos produzidos para a resolução do problema gerador. Nas palavras de M: "Antes de a professora $\mathrm{P}$ explicar o significado das frações unitárias, os alunos já identificavam o desenho no slide e falavam: 'Olha, aquele é a metade!', por exemplo".

Após a aula, as professoras $\mathrm{M}$ e $\mathrm{P}$ realizaram a discussão sobre a aula, destacando os pontos a aprimorar. Sugeriram, por exemplo, propor um problema gerador "mais difícil". A professora $\mathrm{P}$ acredita que tenha subestimado a capacidade dos alunos de resolver problemas, principalmente por alguns deles ainda não serem completamente alfabetizados. Após a discussão, elaboraram uma breve apresentação para relatar suas experiências ao professor formador e às demais participantes da formação. Assim, foi finalizado o ciclo de Estudo de Aula proposto para esta aula planejada e implementada pelas professoras $\mathrm{M}$ e $\mathrm{P}$.

\section{Considerações Finais}

Conforme dito anteriormente, o presente trabalho refere-se a um recorte de uma pesquisa de doutorado em desenvolvimento. Retomamos, aqui, o objetivo de pesquisa, que é investigar 
como o desenvolvimento de uma formação continuada de professores, em um ambiente on-line, fundamentado na Metodologia de Ensino-Aprendizagem-Avaliação de Matemática através da Resolução de Problemas, pode contribuir para o ensino de Matemática. Para isso, foram analisados os dados obtidos a partir da execução de um plano de aula sobre frações unitárias, elaborado por duas professoras participantes da formação de professores ofertada na pesquisa.

As análises mostram que a aula ministrada permitiu que o objetivo das professoras fosse atingido, principalmente por promover a compreensão matemática sobre frações unitárias, proveniente das ações dos próprios alunos a partir do problema gerador proposto.

Durante o relato das professoras, observamos que a implementação da aula pela MEAAMARP foi realizada de maneira satisfatória, com algumas características da metodologia adaptadas por conta da necessidade de ministrar a aula de forma remota.

Percebemos as adaptações das professoras, também, nas terminologias adotadas, embora isso não decorra da situação de aula on-line. Frequentemente chamavam o problema gerador de desafio, pois acreditam que o termo problema possa desencorajar os alunos de solucioná-lo. Em diferentes momentos da formação, as próprias professoras mostravam-se temerosas à implementação de determinadas condutas recomentadas nas etapas sugeridas por Allevato e Onuchic (2014). A principal dificuldade manifestada refere-se a proporcionar às crianças realmente momentos de trabalho independente da condução do professor, permitindo que errem e que testem procedimentos, o que está relacionado a propiciar o desenvolvimento da autonomia de trabalho aos alunos. As professoras relatam que por diversas vezes quiseram interferir na construção das respostas dos alunos por perceberem que estavam erradas. Acreditamos que existe pouca valorização das atividades em que os alunos "trabalham sozinhos", possivelmente porque o professor não se sente útil ou porque não percebe os esforços ou a importância dos esforços dos alunos para a resolução do problema ou, até mesmo, porque não concebe o erro como parte integrante e importante do processo de aprendizagem. Durante as falas das professoras, percebíamos que consideravam como aula, de fato, o momento da formalização, ou seja, o momento mais tradicional da aula, no qual o professor "explica" o conteúdo para os alunos, que devem ouvir passiva e atentamente.

Nesse sentido, a implementação da metodologia possibilitou que os professores manifestassem conhecimentos profissionais e saberes da docência, de várias formas, conforme Shulman (1986, 1987). A maior parte dos saberes considerados neste estudo figuram de forma implícita na metodologia utilizada na pesquisa, sendo que o "conhecimento dos alunos e suas características" ganhou destaque no episódio em que aflorou a dificuldade de alguns alunos na leitura do problema. Ademais, os fatos que ocorreram na implementação da aula, bem como as reflexões desenvolvidas pelas professoras, compartilhadas com as demais participantes da 
formação, sugerem que a experiência e a formação possibilitaram a construção de conhecimento profissional pelos professores e de conhecimento matemático pelos alunos, no decurso da resolução e das discussões sobre o problema proposto, em que atuaram como protagonistas de sua própria aprendizagem.

Todos esses aspectos foram objeto de reflexão durante a formação e durante a socialização da aula com as outras professoras. Com a implementação da MEAAMARP, esperamos que as professoras tenham consolidado seus conhecimentos pedagógicos e que essa metodologia de ensino se torne parte do cotidiano em suas salas de aula de Matemática.

\section{Referências}

ALLEVATO, N. S. G.; ONUCHIC, L. R. Ensino-Aprendizagem-Avaliação de Matemática: Por que através da Resolução de Problemas. In: ONUCHIC, L. R.; ALLEVATO, N. S. G.; NOGUTI, F. C. H.; JUSTULIN, A. M. (org.). Resolução de Problemas: Teoria e Prática. Jundiaí, SP: Paco Editorial, 2014.

ALLEVATO, N. S. G.; ONUCHIC, L. de la R. Ensino-Aprendizagem-Avaliação de Matemática: por que através da resolução de problemas? In: ONUCHIC, L. de la R.; ALLEVATO, N. S. G.; NOGUTI, F. C. H.; JUSTULIN, A. M. (org.). Resolução de Problemas: teoria e prática. 2. ed. Jundiaí, SP: Paco Editorial, 2021. (Em vias de publicação).

BORELLI, S. S. Estudos de Aula na formação de professores de Matemática em turmas de $7^{\circ}$ ano do Ensino Fundamental que ensinam Números. Orientadora: Edda Curi. 2019. 247 f. Tese (Doutorado em Ensino de Ciências e Matemática) - Universidade Cruzeiro do Sul, São Paulo, 2019.

BRASIL. Ministério da Educação. Base Nacional Comum Curricular: Educação é a Base. Brasília: MEC/CONSED/UNDIME, 2018. Versão completa. Disponível em: http://basenacionalcomum.mec.gov.br. Acesso em: 4 set. 2020.

FIORENTINI, D. Formação de professores a partir da vivência e da análise de práticas exploratório-investigativas e problematizadoras de ensinar e aprender matemática. In: CONFERÊNCIA INTERAMERICANA DE EDUCAÇÃO MATEMÁTICA, 13., 2011, Recife, PE. Anais [...]. [S. I.]: CIAEM-IACME, 2011. Disponível em: http://xiii.ciaemredumate.org/index.php/xiii ciaem/xiii ciaem/paper/viewFile/2890/1188. Acesso em: 4 set. 2020.

GOLDENBERG, M. A arte de pesquisar: como fazer pesquisa qualitativa em Ciências Sociais. Rio de Janeiro, RJ: Record, 2011. E-book.

NCTM. Principles and Standards for School Mathematics. Reston, VA: National Council of Teachers of Mathematics, 2000.

ONUCHIC, L. R.; ALLEVATO, N. S. G.; NOGUTI, F. C. H.; JUSTULIN, A. M. (org.). Resolução de Problemas: teoria e prática. Jundiaí, SP: Paco Editorial, 2014.

POLYA, G. A arte de resolver problemas: um novo enfoque do método matemático. Tradução e adaptação de Heitor Lisboa de Araújo. 2. ed. Rio de Janeiro, RJ: Interciência, 1994. 
PONTE, J. P.; BATISTA, M.; VELEZ, I.; COSTA, E. Aprendizagens profissionais dos professores através dos estudos de aula. Perspectivas da Educação Matemática, v. 5, n. temático, p. 7-24, 2012. Disponível em: http://hdl.handle.net/10451/22605. Acesso em: 1 dez. 2021.

SHULMAN, L. S. Those who understand: knowledge growth in teaching. Educational Researcher, v. 2, n. 15, p. 4-14, 1986. DOI: https://doi.org/10.3102/0013189X015002004.

SHULMAN, L. S. Knowledge and teaching: foundation of the new reform. Harvard Educacional Review, v. 1, n. 57, p. 1-22, 1987.

UTIMURA, G. Z. Conhecimento profissional de professoras de $4^{\circ}$ ano centrado no ensino dos números racionais positivos no âmbito do estudo de aula. Orientadora: Edda Curi. 2019. 195 f. Tese (Doutorado em Ensino de Ciências e Matemática) - Universidade Cruzeiro do Sul, São Paulo, 2019.

VAN DE WALLE, J. A. Matemática no Ensino Fundamental: formação de professores e aplicação em sala de aula. Tradução de Paulo Henrique Colonese. 6. ed. Porto Alegre: Artmed, 2009. 